\title{
Hamstrings stretch reflex in human spasticity
}

\author{
DAVID BURKE ${ }^{1}$, J. D. GILLIES ${ }^{2}$, AND JAMES W. LANCE \\ From the Division of Neurology, The Prince Henry Hospital, Sydney, and the School of Medicine, University \\ of New South Wales, Australia
}

SUMMARY In 16 patients with spastic paralysis the hamstrings stretch reflex was found to increase as the velocity of stretch increased, and generally to subside after movement ceased. These effects are attributable to the dynamic property of the primary spindle ending. The stretch reflex commonly appeared in only the last third of the stretching movement and was maximal as the knee became fully extended. This is consistent with the static properties of the primary and secondary spindle endings, and accounts for the absence of the clasp-knife phenomenon in the spastic hamstrings. The difference in the nature of the stretch reflex in spastic flexor and extensor muscles is best explained by the differential reflex effects of group II afferent fibres which facilitate flexor motoneurones and inhibit extensor motoneurones.

There appears to be little difference in the properties of muscle spindles of flexor and extensor muscles or in their sensitivity to dynamic and static fusimotor control (Brown, Crowe, and Matthews, 1965; Lennerstrand, 1968; Lennerstrand and Thoden, 1968a, 1968b). However, the reflex effects of the secondary endings of flexor and extensor spindles differ. With extensor spindles, activation of the secondary ending produces autogenic inhibition of extensor motoneurones, so that the effects of the primary and secondary endings are antagonistic. With flexor spindle endings the effects are synergistic, since activation of flexor secondary endings produces autogenic facilitation (Hunt and Perl, 1960). The stretch reflexes of flexor and extensor muscles should therefore respond in a different manner to change in muscle length.

In a recent study of the spastic quadriceps muscle it was found that the stretch reflex decreased as the muscle was stretched, producing the clasp-knife phenomenon, presumably as a result of stimulation of secondary endings (Burke, Gillies, and Lance, 1970). A similar analysis of the stretch reflex of the hamstrings muscles in human spasticity has now been undertaken.

${ }^{1}$ Commonwealth Postgraduate Scholar and Adolph Basser Research F'llow in Neurology.

${ }^{2}$ Research Scholar of the National Health and Medical Research Council of Australia.

\section{MATERIALS AND METHODS}

Sixteen subjects were examined. Eight were paraplegic or quadriplegic after trauma to the spinal cord, and one was paraplegic as a result of a spinal cord angioma. In five of the subjects, the spinal cord lesion was clinically complete. Five subjects suffered from multiple sclerosis and two from familial spastic paraplegia. In all patients the clinical condition appeared to be static.

The subjects were examined when lying prone. The electromyogram (EMG) produced by passive stretch of the hamstrings muscles was recorded by belly/tendon surface electrodes $10 \mathrm{~cm}$ apart, and integrated (time constant $0.2 \mathrm{sec}$ ). The position of the knee joint was measured by a goniometer, whose output was differentiated (time constant $5 \mathrm{msec}$ ) to produce a voltage proportional to angular velocity. The direct EMG, integrated EMG, joint angle, and angular velocity were recorded on a four-channel Offner dynograph. The direct EMG was monitored on an oscilloscope to detect artefact. Joint angle was also monitored so that any given muscle length could be reproduced.

Two methods of linear stretching were used. To determine the effect of the length of the stretching movement, stretches were commenced from varying degrees of knee flexion, each movement ending with the knee fully extended. To determine the sensitivity of the stretch reflex at different muscle lengths, the stretching movement from flexion to full extension was divided into three sequential steps of equal amplitude. The velocity of stretch was maintained approximately constant during each movement, and each sequence was repeated at different velocities. 
Sinusoidal movements were used to confirm the results of linear stretching. The centre of oscillation was varied systematically, while the velocity and amplitude remained constant. Amplitudes of approximately $20^{\circ}$ and $40^{\circ}$ were studied over a range of velocities.

The peak integrated EMG of the hamstrings was plotted against velocity of stretch, and the calculated line of best fit was determined by regression analysis of those movements which produced EMG. The threshold velocity required to produce a stretch reflex was taken as the intercept of the line of best fit on the velocity axis. Separate calculations were made for the data obtained at each starting angle (initial muscle length). Analysis of covariance was performed to determine the significance of any change in the EMG: velocity relationship following change in the initial muscle length. Probability values were calculated from the variance ratio (F) distribution.

\section{RESULTS}

STRETCH REFLEX IN SPASTIC HAMSTRINGS On clinical examination in all patients, the resistance to stretch progressively increased as the hamstrings were stretched, was maximal when the muscles were fully stretched, and subsided after movement had ceased. The clasp-knife phenomenon was not observed.

On repeated testing, the stretch reflex fatigued until, in most patients, a stable base-line was reached. In a few patients spasms frequently interrupted the examination and it was therefore difficult to obtain a stable base-line because stretch reflexes were generally increased after spasm. In the prone position these spasms commonly involved both flexor and extensor muscles, and the limb often became rigid in extension for the duration of the spasm. These spasms were more frequent in patients with complete cord lesions, and were precipitated by extending the knee. Flexing the knee to $90^{\circ}$ was usually sufficient to control the spasms.

VELOCITY OF STRETCH The relationship between the velocity of linear stretch and hamstrings EMG was examined at several starting angles between $30^{\circ}$ and $135^{\circ}$ of flexion. In a few patients with marked spasticity, even the slowest movement evoked a stretch reflex, but in most subjects a threshold velocity could be determined, below which no stretch reflex was produced. In either instance, the hamstrings stretch reflex increased with increasing velocity of passive stretch (Fig. 1).

At velocities below $300 \% \mathrm{sec}$, this relationship appeared linear (Fig. 2), but in seven patients faster velocities of stretch produced a disproportionately greater reflex response. In one patient the stretch reflex appeared to reach a plateau as movements became faster, but this was not observed in any other patient.

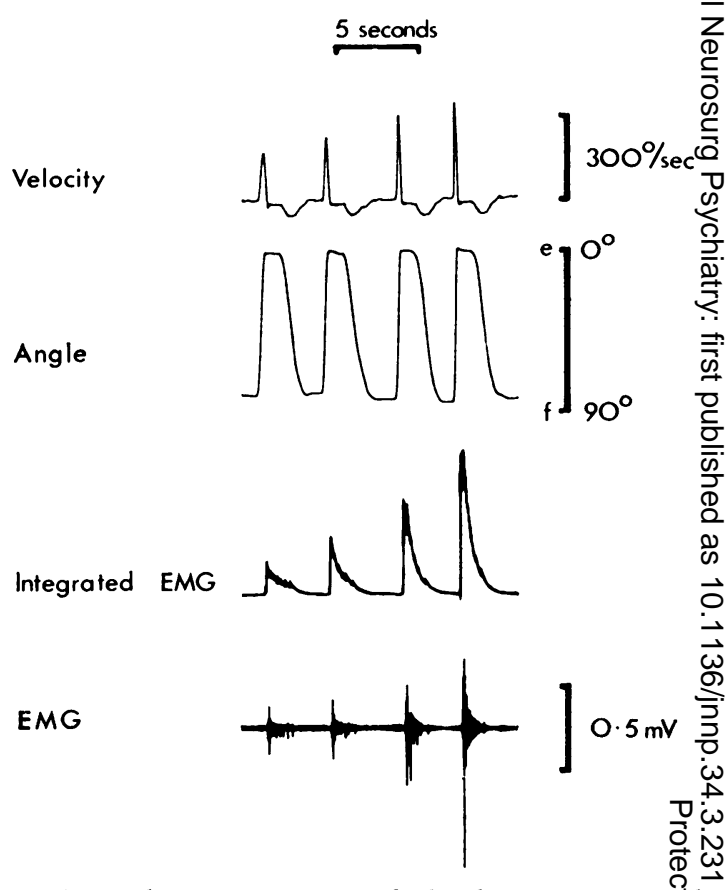

FIG. 1. Velocity sensitivity of the hamstrings stree reflex. With increasing velocity of linear stretch, the hat? strings stretch reflex increases, as seen by the increasting EMG response. As in all other diagrams, stretching $i 5$ represented by an upward deflection of the trace.

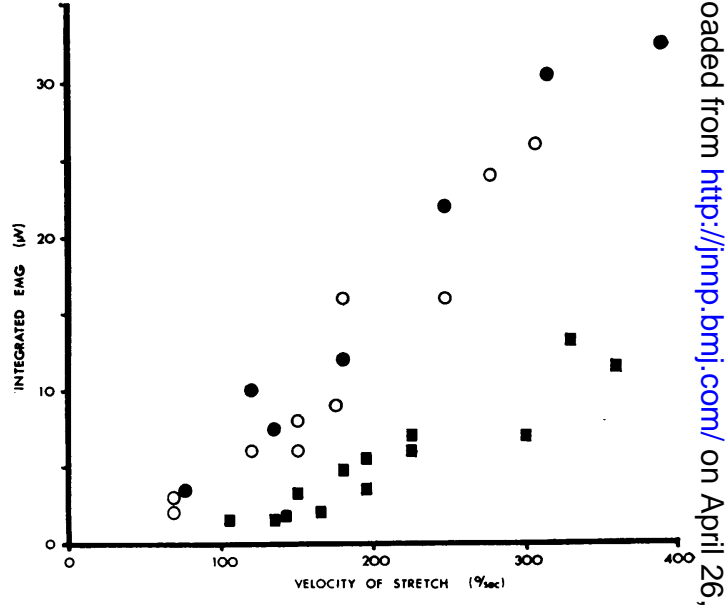

FIG. 2. Linearity of the EMG: velocity relationshipN Each symbol represents a separate patient. In each of th\&్ three patients the reflex response appears linearly related to the stretching velocity. 
A similar relationship between velocity of stretch and reflex EMG was found at each starting angle and there was no significant difference between the relationships at each angle $(P>0 \cdot 20)$. The threshold velocity and the slope of the EMG: velocity relationship were thus not influenced by change in the initial muscle length (Fig. 3).

During sinusoidal movements of the limbs, an increase in stretch reflex was observed with increase in the peak velocity of the movement (Fig. 4a, b).

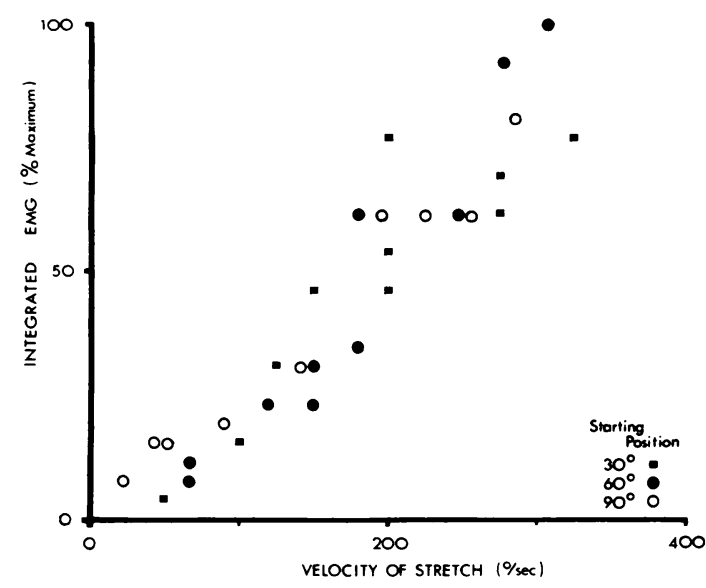

FIG. 3. Lack of effect of varying initial muscle length on the EMG : velocity relationship. No significant difference in the relationship has been produced by starting the movement from a different position.
Within the range of peak velocities used, up to $200^{\circ} / \mathrm{sec}$, the relationship was again linear (Fig. 5).

INITIAL MUSCLE LENGTH With linear stretching a change in amplitude of the stretching movement did not alter the resulting stretch reflex, provided that the movements were carried through until the knee was fully extended (Fig. 3). With sinusoidal stretching, increase in amplitude of the cycle did not increase the amount of EMG provided that the peak velocity remained constant (Fig. 4b, c).

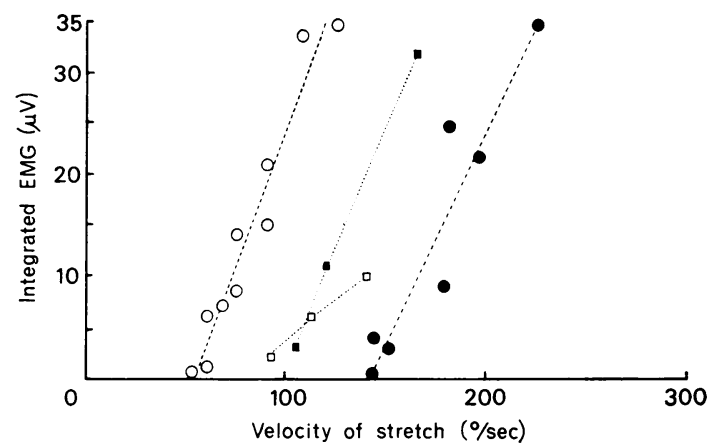

FIG. 5. EMG : velocity relationship with sinusoidal stretching. Each symbol represents a separate patient. In each of the four patients, the peak EMG produced at the most extended position of the knee appears linearly related to the peak velocity of the sinusoidal stretching cycle.
a
b
C

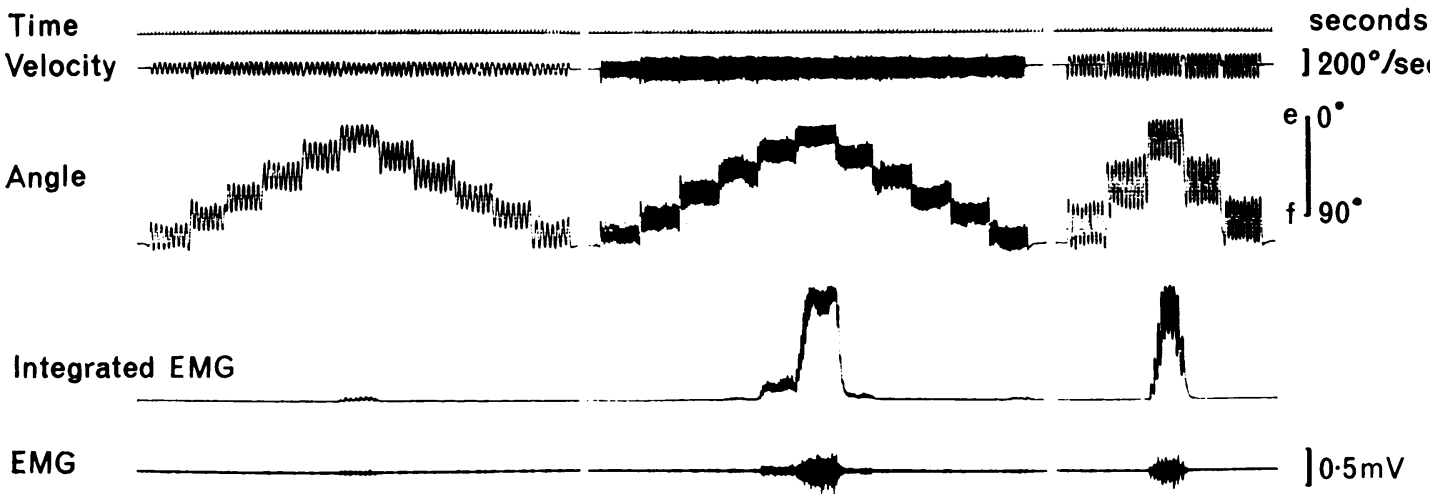

FIG. 4. Sinusoidal stretching of the hamstrings. (a) and (b) illustrate that the reflex depends on the velocity of stretch, the peak velocity of the sinusoidal movement being greater in (b). (b) and (c) show that doubling the amplitude of the sinusoidal cycle does not produce a greater stretch reflex if the peak velocity remains constant. In each record, all from the same patient, the stretch reflex is produced only when the muscles are almost fully stretched. In (b), it can be seen that this dependence on the degree of stretch is a graded phenomenon. 
With stepwise linear stretching at a constant velocity, EMG was usually produced only by the third step of the movement, which reached the fully stretched position (Fig. 6). Occasionally, at high velocities of stretch, a small EMG response could be obtained during the intermediate step. At no time was there any EMG response during the first step. With sinusoidal movements, the stretch reflex was maximal when the limb was oscillating in the extended position. As the point of oscillation was moved to a less extended position, the stretch reflex diminished (Fig. 4). This effect was observed with both amplitudes of movement and at all velocities.

DURATION OF STRETCH REFLEX In most patients the stretch reflex died away after movement ceased, although the muscle remained stretched. The time taken for the EMG to subside was variable, especially after spasms, but was generally 1 to $2 \mathrm{sec}$. In two patients, the EMG decreased over 4 to $8 \mathrm{sec}$ and a low voltage $F M G$ persisted. In another patient the stretch reflex was well maintained after cessation of movement (Fig. 7). In these three patients, the EMG activity ceased on flexion of the knee. Of the three, one had an incomplete traumatic lesion of the spinal cord and two had multiple sclerosis.

\section{DISCUSSION}

At velocities of stretch less than $300^{\circ} / \mathrm{sec}$ the stretch

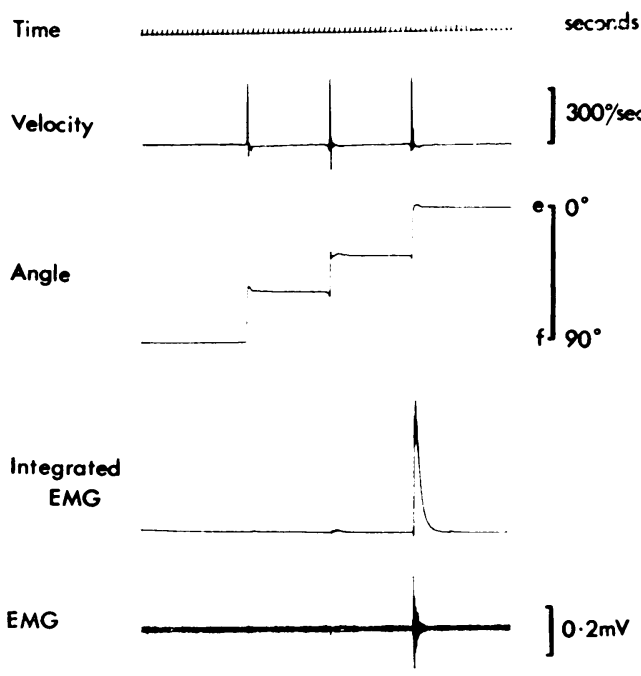

FIG. 6. Stepwise linear stretching. Sequential stepwise stretching movements of approximately equal amplitude and constant velocity. A significant stretch reflex is produced only in the last step which approaches the fully stretched length.

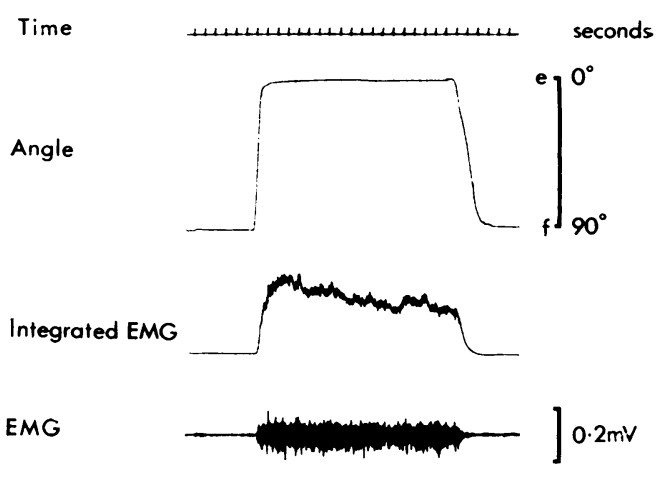

FIG. 7. Static stretch reflex. A static stretch reflex on maintained stretch, subsiding when the knee was flexed, क्ञ in a patient suffering from multiple sclerosis.

reflex of the spastic hamstrings muscle has beens shown to augment linearly with increasing velocityo once a threshold had been exceeded. This relation $-\omega$ ship is similar to that found at all velocities Bf stretch in the spastic quadriceps muscle (Burke et $\$$ \% 1970) and presumably results from the dynanilc sensitivity of the primary spindle ending (Jansen aods Matthews, 1962; Brown et al., 1965; Lennerstrau $\vec{r}$ 1968). The nonlinearity at velocities exceeding $300^{\circ} \mathrm{C}$ $\mathrm{sec}$ in some subjects is unexplained but is unlike to be of significance, since such velocities excescto those of physiological movement.

The stretch reflex was produced only in the lasi part of the stretching movement, appearing earliere if the velocity of stretch was increased. Within thiso last part of the stretching movement, the dependence्यु on length was a graded phenomenon, as seen in Fig $4 \mathrm{~b}$, and either the primary or the secondary spindle ending could be responsible for this effect, sincee both are sensitive to length (Jansen and Matthews 1962; Bessou and Laporte, 1962; Lennerstrand 1968). However because of the short range of move + ment over which the stretch reflex was produced, the contribution of increasing muscle length could not be assessed quantitatively.

The resistance to passive movement produced by the stretch reflex was maximal as the hamstring became fully stretched, so that no clasp-knif phenomenon was noted. By way of contrast, the clasp-knife phenomenon is prominent in the spastios quadriceps muscle, since the stretch reflex diminishes. as muscle length increases (Burke et al., 1970). Thâे differing effects of muscle length are consistent with? activity in group II afferent fibres from secondars spindle endings, facilitating flexor reflexes and inhibiting extensor reflexes (Hunt, 1952, 1954Q్ 
Laporte and Lloyd, 1952; Eccles and Lundberg, 1959a; Hunt and Perl, 1960).

Eccles and Lundberg (1959a) were unable to demonstrate flexor reflex afferent effects from stimulation of large joint afferent nerve fibres of low threshold, although such effects could be obtained with stimuli two to four times threshold. Skoglund (1956) found that physiological stimulation of the knee joint produced only small and inconsistent reflex effects. It is therefore unlikely that joint afferent fibres significantly affect the hamstrings stretch reflex. Since Golgi tendon organs respond selectively to active contraction of muscle (Jansen and Rudjord, 1964; Houk and Henneman, 1967), and have the same autogenic inhibitory effect on flexors as on extensors (Bianconi, Granit, and Reis, 1964), activation of these receptors could not explain the different characteristics of the hamstrings and quadriceps stretch reflexes.

The presence of a sustained reflex in response to maintained stretch in three patients can be attributed either to static fusimotor drive, increasing the static response of the primary and secondary endings (Brown et al., 1965; Lennerstrand and Thoden, $1968 \mathrm{~b}$ ), or to disinhibition of the group II afferent pathway (Eccles and Lundberg, 1959b; Holmqvist and Lundberg, 1959, 1961). Patients with complete spinal cord lesions in whom one would expect disinhibition of the group II pathway to be maximal (Holmqvist and Lundberg, 1959) did not show a sustained response to stretch, presumably because static fusimotor activity is minimal (Alnaes, Jansen, and Rudjord, 1965). It is therefore apparent that disinhibition of the group II afferent pathway is not in itself sufficient to produce a static stretch reflex. In view of this, increased activity in static fusimotor fibres appears the more likely explanation of the static stretch reflex found in the three patients described, all of whom had partial upper motor neurone lesions.

The authors wish to thank the National Health and Medical Research Council of Australia and the Adolph Basser Trust for their continuing support of this project. Financial assisiance from Mr. and Mrs. Edwin Street, The Rockdale Lions Club, and Ciba Co. Pty. Ltd. is gratefully acknowledged. Mr. P. D. Neilson, Mr. K. Norcross, and Mr. N. Skuse have assisted with technical problems. Illustrations were prepared by the Department of Medical Illustration, University of New South Wales.

\section{REFERENCES}

Alnaes, E., Jansen, J. K. S., and Rudjord, T. (1965). Fusi- motor activity in the spinal cat. Acta physiol. scand., 63, 197-212.

Bessou. P., and Laporte, Y. (1962). Responses from primary and secondary endings of the same neuromuscular spindle of the tenuissimus muscle of the cat. In Symposium on Muscle Receptors, pp. 105-119. Edited by D. Barker, Hong Kong University Press: Hong Kong.

Bianconi, R., Granit, R., and Reis, D. J. (1964). The effects of flexor muscle spindles and tendon organs on homonymous motoneurones in relation to $\gamma$-bias and curarization. Acta physiol. scand., 61, 348-356.

Brown, M. C., Crowe, A., and Matthews, P. B. C. (1965). Observations on the fusimotor fibres of the tibialis posterior muscle of the cat. J. Physiol. (Lond.), 177, 140159.

Burke, D., Gillies, J. D., and Lance, J. W. (1970). The quadriceps stretch reflex in human spasticity. $J$. Neurol. Neurosurg. Psychiat. 33, 216-223.

Eccles, R. M., and Lundberg, A. (1959a). Synaptic actions in motoneurones by afferents which may evoke the flexion reflex. Arch. ital. Biol., 97, 199-221.

Eccles, R. M., and Lundberg, A. (1959b). Supraspinal control of interneurones mediating spinal reflexes. J. Physiol. (Lond.), 147, 565-584.

Holmqvist, B., and Lundberg, A. (1959). On the organization of the supraspinal inhibitory control of interneurones of various spinal reflex arcs. Arch. ital. Biol., 97, 340-356.

Holmqvist, B., and Lundberg, A. (1961). Differential supraspinal control of synaptic actions evoked by volleys in the flexion reflex afferents in alpha motoneurones. Acta. physiol. scand., 54, Suppl. 186, 1-51.

Houk, J., and Henneman, E. (1967). Responses of Golgi tendon organs to active contractions of the soleus muscle of the cat, J. Neurophysiol., 30, 466-481.

Hunt, C. C. (1952). The effect of stretch receptors from muscle on the discharge of motoneurones. J. Physiol. (Lond.), 117, 359-379.

Hunt, C. C. (1954). Relation of function to diameter in afferent fibers of muscle nerves. J. gen. Physiol., 38, 117131.

Hunt, C. C., and Perl, E. R. (1960). Spinal reflex mechanisms concerned with skeletal muscle. Physiol. Rev., 40, 538-579.

Jansen, J. K. S., and Matthews, P. B. C. (1962). The central control of the dynamic response of muscle spindle receptors. J. Physiol. (Lond.), 161, 357-378.

Jansen, J. K. S., and Rudjord, T. (1964). On the silent period and Golgi tendon organs of the soleus muscle of the cat. Acta physiol. scand., 62, 364-379.

Laporte, Y., and Lloyd, D. P. C. (1952). Nature and significance of the reflex connections established by large afferent fibers of muscular origin. Amer. J. Physiol., 169, 609-621.

Lennerstrand, G. (1968). Position and velocity sensitivity of muscle spindles in the cat. I. Primary and secondary endings deprived of fusimotor activation. Acta physiol. scand., 73, 281-299.

Lennerstrand, G., and Thoden, U. (1968a). Position and velocity sensitivity of muscle spindles in the cat. II. Dynamic fusimotor single-fibre activation of primary endings. Acta physiol. scand., 74, 16-29.

Lennerstrand, G., and Thoden, U. (1968b). Position and velocity sensitivity of muscle spindles in the cat. III. Static fusimotor single-fibre activation of primary and secondary endings. Acta physiol. scand., 74, 30-49.

Skoglund, S. (1956). Anatomical and physiological studies of knee joint innervation in the cat. Acta physiol. scand., 36, Suppl. 124, 1-101. 